\title{
Clinical Characteristics of Peripheral Neuropathy in Kenyan Patients with HIV Infection Compared with Patients with Concurrent HIV Infection and Diabetes Mellitus
}

\author{
Werimo Pascal Kuka (D) · Jasmit Shah · Uazman Alam • \\ Reena Shah · Dilraj Singh Sokhi
}

Received: November 1, 2021 / Accepted: January 14, 2022 / Published online: February 14, 2022

(c) The Author(s) 2022

\begin{abstract}
Introduction: Persons living with human immunodeficiency virus (HIV) are living longer and at risk of non-communicable diseases, including diabetes mellitus (DM). Both HIV and DM place patients at risk of peripheral neuropathy (PN). Our aim was to demonstrate the prevalence and characteristics of $\mathrm{PN}$ in our population of patients with HIV infection compared with concomitant HIV and DM.

Methods: A prospective cross-sectional study was performed at the Aga Khan Hospital in Nairobi, Kenya. Data were collected on

Supplementary Information The online version contains supplementary material available at https:// doi.org/10.1007/s13300-022-01205-3.
\end{abstract}

W. P. Kuka $(\varangle) \cdot$ J. Shah · R. Shah · D. S. Sokhi Department of Medicine, Aga Khan University Medical College East Africa, 4th Floor East Tower Block, Third Avenue Parklands, P.O. Box 30270, Nairobi 00100, GPO, Kenya

e-mail: wpkuka@yahoo.com

\section{U. Alam}

Division of Endocrinology, Diabetes and Gastroenterology, University of Manchester, Manchester, UK

\section{U. Alam}

Diabetes and Endocrinology Research, Institute of Life Course and Medical Sciences and the Pain Research Institute, University of Liverpool and Liverpool University Hospital NHS Foundation Trust, Liverpool, UK demographics and characteristics of DM and HIV. Symptoms and signs of PN were evaluated by Neuropathy Symptom Score, Neuropathy Disability Score, and $10 \mathrm{~g}$ monofilament testing. Results: Two groups were recruited, each consisting of 68 patients: (1) HIV only, (2) HIV and DM. The median age of patients was 51 years (IQR 42.8-58.6) and 55\% were male. Median duration for HIV was 10 years (IQR 5-12) with a median CD4 count of 524 cells $/ \mathrm{mm}^{3}$ (IQR 369-731). Median duration for DM was 1 year with a median glycosylated hemoglobin of $6.7 \%$ (IQR 6.6-7.6). Sixty-nine percent of patients with HIV had suppressed viral loads, and 9 patients $(6.6 \%)$ had a history neurotoxic antiretroviral therapy use. PN was detected in 11 (16\%) HIV-only patients, and in 17 (25\%) participants who had both HIV and DM (Fisher exact test chi-square $=0.4$ ). Univariate analysis demonstrated older age, high body mass index, and long duration of HIV were associated with an OR of 1.07 (95\% CI 1.02-1.11), 1.21 (95\% CI $0.46-3.11)$, and 1.07 (95\% CI 0.99-1.15) in the overall group, respectively.

Conclusion: Our study demonstrates a higher but non-significant prevalence of $\mathrm{PN}$ in patients with both HIV and DM when compared to HIV alone. HIV disease control had no association with PN presence.

Keywords: Peripheral neuropathy; HIV; Diabetes; Kenya 


\section{Key Summary Points}

The prevalence of human immunodeficiency virus (HIV) is high in sub-Saharan Africa, a region which also has a huge burden of undiagnosed diabetes mellitus (DM).

The study aimed to establish the prevalence of and risk factors for peripheral neuropathy (PN), a complication of both HIV and DM, in patients with both these chronic conditions.

Results from the study showed a higher burden of PN in patients with both HIV and DM compared with HIV alone.

The study identified old age, high BMI, and long duration of HIV as risk factors for development of PN in the study population.

This forms the basis for future projects on quality of life in patients with PN and living with concurrent HIV and DM.

\section{INTRODUCTION}

The population infected with human immunodeficiency virus (HIV) is ageing and will increasingly develop non-communicable diseases [1]. Antiretroviral therapy (ART) has lessened the burden of morbidity and mortality amongst people living with HIV [2, 3]. Prophylaxis against opportunistic infections and the prevention of mother to child transmission of HIV have resulted in increased life span of patients with HIV and higher child survival gains, respectively [4]. In Kenya, these factors have resulted in a reduction of acquired immunodeficiency syndrome (AIDS)-related deaths by $48 \%$ since 2010 . The current prevalence of HIV in the country is $4.9 \%$ [5].

Noninfectious comorbidities including diabetes mellitus (DM) have a higher prevalence in
HIV-positive patients than in age-matched controls $[6,7]$. The prevalence of DM has been rapidly increasing in middle- and lower-income countries and it is predicted that the number of adults living with DM in Africa will more than double between 2017 and 2045. The region is also estimated to have the highest number of undiagnosed cases of DM. In Kenya, the prevalence is estimated at $2 \%$ [8].

HIV and DM demonstrate a bidirectional effect on each other. Poor glycemic control occurs in HIV-positive patients with type $2 \mathrm{DM}$ [9]. A positive association has been demonstrated between antiretroviral drugs that cause lipodystrophy and the development of DM [10]. Neuropathy can occur independently in both HIV infection and DM. The main pattern of HIV infection is distal symmetric polyneuropathy (DSP) primarily of a small (c) fiber origin, which has similar features to diabetic neuropathy [11]. The prevalence of HIV neuropathy from a systematic review showed great variation with estimates ranging from $1.2 \%$ to $69.4 \%$ [12]. The proposed etiologies of DSP in HIV are peripheral nerve injury associated with the presence of HIV in the immune cells component of the peripheral nerves [13] and neurotoxic effects of antiretroviral drugs. Studies about the association among CD4 count, viral load, and risk of peripheral neuropathy ( $\mathrm{PN}$ ) have been conflicting $[14,15]$. Diabetic neuropathy is the most common cause of PN worldwide [16]. DSP is a clinical diagnosis that is suggested by the presence of typical symptomatology and symmetrical distal sensory loss or typical signs in the absence of symptoms in a patient with DM [17].

The continued survival of people living with HIV predisposes them to age-related comorbidities as well as side effects from the use of ART. Many HIV neuropathy studies exclude patients with DM. Therefore, the interaction has been poorly described. This study aims to investigate the combination of risk factors demonstrated to be associated with PN in HIV with or without DM. The prevalence of neuropathy in patients will provide a basis for future investigations into the health status and quality of life amongst the growing number of age-related comorbidities in persons living with HIV/AIDS. 


\section{METHODS}

The study was conducted at the Aga Khan University Hospital, Nairobi (AKUHN), a private nonprofit teaching hospital. The facility has international accreditation by the Joint Commission International, and the laboratory has been accredited by the South African National Accreditation System (SANAS) and the College of American Pathologists. An average of 700 patients are followed up per year at the infectious disease clinic of the institution. CD4 counts and HIV viral load testing are performed at baseline and every 6 months. Metabolic panels including glycated hemoglobin (HbA1c), lipid profile, and renal and liver function tests are performed annually.

\section{Study Participants}

Eligible participants were at least 18 years old and assigned to one of two groups: (1) HIV positive; (2) both HIV positive and with DM. Exclusion criteria included a history of neuropathy due to non-HIV or non-diabetic cause, namely alcoholism, amyloidosis, autoimmune disorders, chronic kidney failure, connective tissue disease, infectious disease, liver failure, and vitamin $B_{12}$ deficiency.

\section{Protocol Approval and Patient Consent}

Ethical approval was sought from the Institutional Ethics and Review Committee at the AKUHN (Ref. No. 2018/REC-121) prior to conducting the study. The study was conducted in accordance with the Declaration of Helsinki 1964 and its later amendments. Informed consent was signed by the participants prior to enrollment into the study.

\section{Study Procedures}

This was a prospective, cross-sectional study that enrolled patients from August 2020 to March 2021. Demographic, clinical, and laboratory data were obtained from the patient's records. Each consenting participant was tested for the presence of PN using both a questionnaire for symptoms and clinical testing. The Neuropathy Symptom Score (NSS) (see Supplementary Material) was administered which is a validated tool to diagnose the presence and severity of neuropathy. It consists of questions probing for gait instability, burning sensation, numbness, pricking sensation and autonomic symptoms [18]. A clinical examination was undertaken by application of components of the Neuropathy Disability Score (NDS) (see Supplementary Material) and monofilament testing using a 10-g nylon filament. Neuropathy testing was performed by an internal medicine resident after training by a neurologist (D.S.) and an endocrinologist (U.A.). The NDS is a validated tool that evaluates both small and large fiber neuropathy in the lower limbs by testing the perception of pain, vibration, temperature, and ankle reflexes [1].

Peripheral neuropathy was defined as at least one neuropathy symptom on the NSS and at least one sign on either the NDS or a positive monofilament testing.

\section{Statistical Analysis}

Categorical data such as gender, ethnicity, and alcohol use are presented as frequencies and percentages, whereas continuous data such as age, body mass index (BMI), CD4 count, HIV viral load, and current $\mathrm{HbA} 1 \mathrm{c}$ are presented as medians and interquartile ranges (IQR). Continuous data was further tested for normality using Shapiro-Wilk test. Univariate analyses were conducted using Fisher's exact test for categorical variables and Kruskal-Wallis test for continuous variables when comparing the associations between the two groups (HIV vs HIV with DM). A logistic regression model was used to estimate the association between the risk factors and peripheral neuropathy status. The electronic database of the commercially available Statistical Package for Social Sciences (SPSS) version 25 was used to perform the analysis. Variables with a $p$ value of less than 0.10 were included in the multivariate model whereas a $p$ value of less than 0.05 was considered significant. 


\section{RESULTS}

A total of 150 patients were assessed for eligibility for inclusion into the study. Five patients declined consent, four were ineligible owing to meeting exclusion criteria, and five were excluded from the study because of inadequate data. Therefore 136 patients, with 68 in each study group, were included in the final analysis. Figure 1 depicts the flow of the study.

\section{Demographic Characteristics of Study Population}

The median age of the participants in the HIV and DM group was higher at 55.6 years (IQR 47.2-60.4) than the 51.0 years (IQR 42.3-58.6) in the HIV only category $(p<0.001)$. Fifty-five percent $(n=75 / 136)$ of the total participants were male, accounting for $51.5 \%$ and $46.9 \%$ in the HIV-only and concurrent HIV and DM groups, respectively. Overall, $98.5 \%$ of the participants were Africans. The other differences in demographic characteristics are detailed in Table 1.

\section{Disease Characteristics}

In the HIV-only and concurrent HIV and DM groups, the median duration since diagnosis of HIV was 8.5 (IQR 4.0-12.0) and 10.5 (IQR 6.0-13.5) years, respectively (Table 2). The current median CD4 count was 490 (IQR 356-680) and 588 (IQR 387-799) in the HIV-only and concurrent HIV and DM groups, respectively $(p=0.087)$. The proportion of patients with either undetectable or less than 20 copies (the laboratory cutoff range) of HIV RNA detected was $69.1 \%$. Ninety-four percent of the total study population were on ART and only nine had a history of use of neurotoxic ART medications. In the concurrent HIV and DM group, the mean duration of period of follow-up for DM was 3.85 years. The average HBA1c was $7.65 \%$.

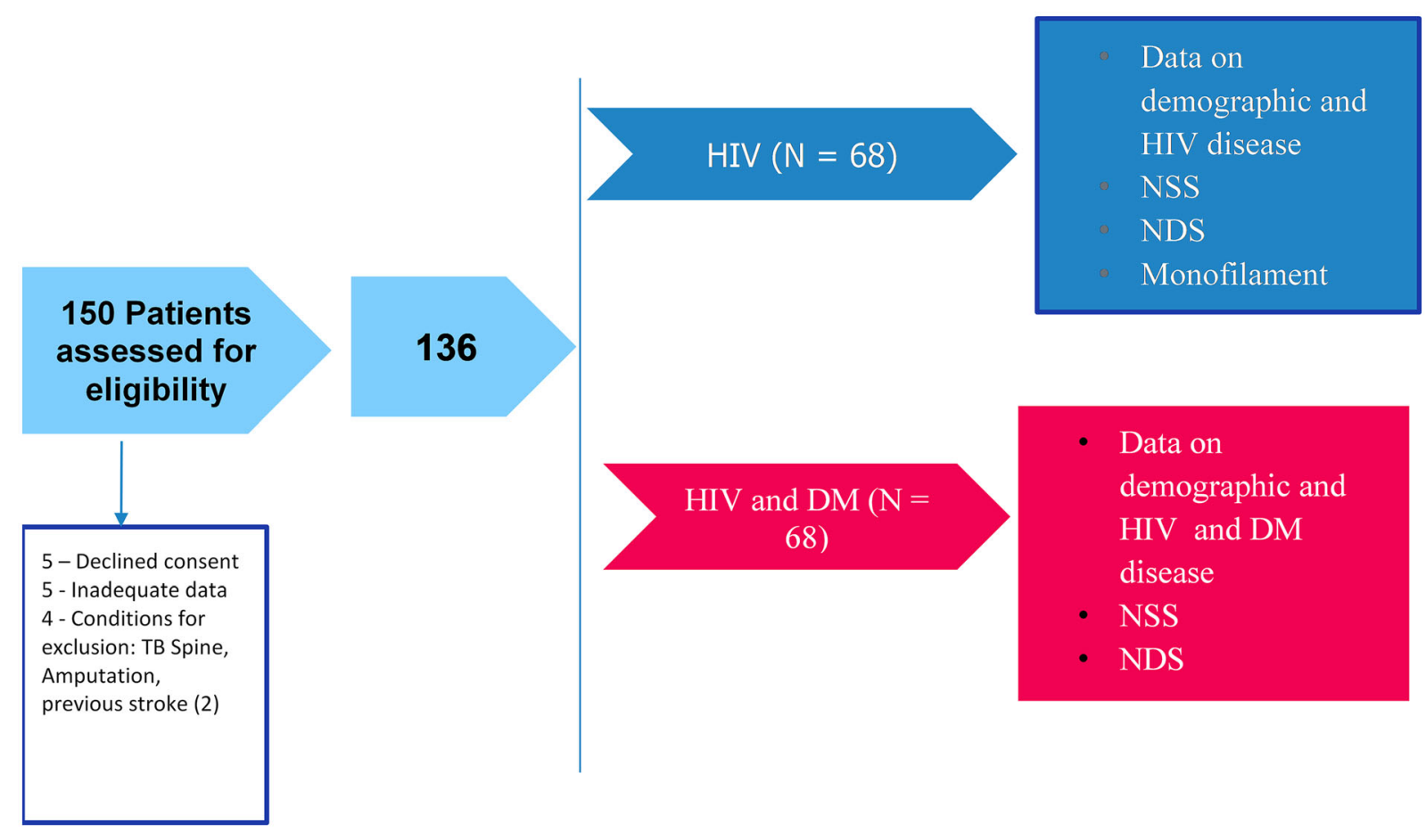

Fig. 1 Study flowchart 
Table 1 Demographic characteristics of study population

\begin{tabular}{|c|c|c|c|c|c|c|c|}
\hline \multirow{3}{*}{$\begin{array}{l}\text { Variables } \\
\text { Age (years) }\end{array}$} & \multirow{2}{*}{\multicolumn{2}{|c|}{$\begin{array}{l}\text { Total } \\
N=136\end{array}$}} & \multirow{2}{*}{\multicolumn{2}{|c|}{$\begin{array}{l}\text { HIV only } \\
N=68\end{array}$}} & \multirow{2}{*}{\multicolumn{2}{|c|}{$\begin{array}{l}\mathrm{HIV}+\mathrm{DM} \\
N=68\end{array}$}} & \multirow{3}{*}{$\begin{array}{l}P \text { value } \\
<0.001\end{array}$} \\
\hline & & & & & & & \\
\hline & 51.0 & {$[42.3,58.6]$} & 46.9 & {$[38.7,53.7]$} & 55.6 & {$[47.2,60.4]$} & \\
\hline \multicolumn{8}{|l|}{ Gender } \\
\hline Male & 75 & $55.1 \%$ & 35 & $51.5 \%$ & 40 & $58.8 \%$ & \multirow[t]{2}{*}{0.491} \\
\hline Female & 61 & $44.9 \%$ & 33 & $48.5 \%$ & 28 & $41.2 \%$ & \\
\hline \multicolumn{8}{|l|}{ Ethnicity } \\
\hline African & 134 & $98.5 \%$ & 66 & $97.1 \%$ & 68 & $100.0 \%$ & \multirow[t]{2}{*}{0.49} \\
\hline Asian & 2 & $1.5 \%$ & 2 & $2.9 \%$ & 0 & $0.0 \%$ & \\
\hline Height $(\mathrm{cm})$ & 169.0 & {$[162.0,174.5]$} & 168.0 & {$[160.0,175.0]$} & 169.5 & {$[162.0,173.0]$} & 0.772 \\
\hline Weight $(\mathrm{Kg})$ & 75.0 & {$[70.0,85.5]$} & 75.0 & {$[70.0,85.0]$} & 77.5 & {$[70.0,88.5]$} & 0.147 \\
\hline
\end{tabular}

$D M$ diabetes mellitus, $H I V$ human immunodeficiency virus

\section{Prevalence of Neuropathy}

Neuropathic symptoms were reported by about a third of the participants, with no significant differences in the two groups (HIV only, 33.8\%; HIV and DM, 30.9\%) (Table 3). The HIV and DM group had a higher proportion of detected abnormalities with $27(39.7 \%)$ patients while the HIV-only group had 16 patients (23.5\%). The most common detected abnormality on neurological examination was absent reflexes. (A detailed table of NDS findings is available in the Supplementary Material.)

The diagnosis of PN required the presence of at least one symptom and at least one sign. This criterion was met by $20.6 \%$ of the participants (HIV only, 16\%; HIV and DM, 25\%; see Fig. 2).

\section{Risk Factors Associated with Neuropathy}

In the overall cohort, older age, BMI and duration of HIV were not significantly associated with PN. Older age had odds ratio (OR) of 1.04; 95\% confidence interval (CI) 0.979-1.102, and OR 1.09 ; 95\% CI 1.019-1.175 in the HIV only and concurrent HIV and DM cohorts, respectively. In the HIV-only group, the period of HIV treatment had an OR 1.08 (95\% CI 0.960-1.219) while the OR was 1.06 (95\% CI 0.962-1.156) in the concurrent HIV and DM group. Both the CD4 count at diagnosis of HIV and the current CD4 count had no effect on the presence of neuropathy in both groups. Suppression of viral load was not associated with peripheral neuropathy in the two groups. The findings are shown in Table 4.

\section{DISCUSSION}

In view of the increasing coexistence of noncommunicable disease in patients with HIV, our study aimed to show the burden of one of the complications of both HIV and DM. We identified an overall prevalence of $20.6 \%$ in the 136 participants. Comparatively, the prevalence in the HIV and DM group was higher than in the HIV-only group $(25.0 \%$ and $16.2 \%$, respectively).

The prevalence of PN in HIV has varied markedly in previous studies depending on the population studied and the diagnostic criteria utilized. Studies that have included both signs and symptoms have shown a range of prevalence of PN in HIV from 4\% to 40\% [15, 19-24]. Most of these reports utilized the Brief PN Screen (BPNS), a validated tool that assesses both the symptoms and signs of neuropathy 
Table 2 Disease characteristics of HIV and diabetes mellitus

\begin{tabular}{|c|c|c|c|c|c|c|c|}
\hline \multirow{3}{*}{$\begin{array}{l}\text { Variables } \\
\text { HIV duration (years) }\end{array}$} & \multirow{2}{*}{\multicolumn{2}{|c|}{$\frac{\text { Total }}{N=136}$}} & \multirow{2}{*}{\multicolumn{2}{|c|}{$\frac{\text { HIV only }}{N=68}$}} & \multirow{2}{*}{\multicolumn{2}{|c|}{$\begin{array}{l}\text { HIV + diabetes } \\
N=68\end{array}$}} & \multirow{3}{*}{$\begin{array}{l}P \text { value } \\
0.071\end{array}$} \\
\hline & & & & & & & \\
\hline & 10.0 & {$[5.0,12.0]$} & 8.5 & {$[4.0,12.0]$} & 10.5 & {$[6.0,13.5]$} & \\
\hline CD4 count at diagnosis & 200.0 & {$[65.5,400.0]$} & 162.5 & {$[50.0,378.0]$} & 242.5 & {$[76.0,429.5]$} & 0.220 \\
\hline Recent CD 4 count & 524.5 & {$[369.0,731.0]$} & 490.0 & {$[356.0,680.0]$} & 588 & {$[387.5,799.0]$} & 0.087 \\
\hline \multicolumn{8}{|l|}{ Recent HIV-1 RNA count } \\
\hline Undetectable $/<20$ & 94 & $69.1 \%$ & 48 & $70.6 \%$ & 46 & $67.6 \%$ & \multirow[t]{2}{*}{0.853} \\
\hline Detectable & 42 & $30.9 \%$ & 20 & $29.4 \%$ & 22 & $32.4 \%$ & \\
\hline \multicolumn{8}{|l|}{ Current ART use } \\
\hline Yes & 129 & $94.9 \%$ & 65 & $95.6 \%$ & 64 & $94.1 \%$ & \multirow[t]{2}{*}{0.648} \\
\hline None & 7 & $5.1 \%$ & 3 & $4.4 \%$ & 4 & $5.9 \%$ & \\
\hline \multicolumn{8}{|c|}{ History of previous neurotoxic ART use } \\
\hline Yes & 9 & $6.6 \%$ & 3 & $4.4 \%$ & 6 & $8.8 \%$ & \multirow[t]{2}{*}{0.493} \\
\hline No & 127 & $93.4 \%$ & 65 & $95.6 \%$ & 62 & $91.2 \%$ & \\
\hline Duration of diabetes (years) & & & - & - & 1.0 & {$[0.5,6.0]$} & - \\
\hline HbAlc (\%) & & & - & - & 6.7 & {$[6.6,7.6]$} & - \\
\hline Total cholesterol $(\mathrm{mmol} / \mathrm{L})$ & & & - & - & 4.5 & {$[3.7,5.2]$} & - \\
\hline HDL cholesterol $(\mathrm{mmol} / \mathrm{L})$ & & & - & - & 1.1 & {$[0.6,1.5]$} & - \\
\hline LDL cholesterol $(\mathrm{mmol} / \mathrm{L})$ & & & - & - & 2.7 & {$[2.2,3.4]$} & - \\
\hline Triglycerides $(\mathrm{mmol} / \mathrm{L})$ & & & - & - & 1.7 & {$[1.2,2.3]$} & - \\
\hline
\end{tabular}

Data are presented as the number (\%) of patients or median (25th and 75 th percentile) values $A R T$ antiretroviral therapy, $H b A 1 c$ glycated hemoglobin, $H D L$ high density lipoprotein, LDL low density lipoprotein, $R N A$ ribonucleic acid

[20]. The prevalence of $20.6 \%$ in the overall cohort of our study is comparable to the range exhibited in the aforementioned reports. Conversely, a high estimate of $59 \%$ was reported in Rwanda by Tumusiime et al. [25] 21\% of the participants were on an ART regime containing a neurotoxic drug, stavudine, compared to our population among whom only $6.6 \%$ reported previous use.

Our study reported a higher prevalence in the HIV and DM group compared to the HIVonly group. Previous studies in the African region have either excluded patients with DM or did not have any patients with a history of DM among their participants. A study done in
South Africa listed DM as an exclusion criterion due to the confounding in the diagnosis of HIVassociated PN [24]. Studies of PN in patients with HIV in Kenya [15] and Uganda [26] did not include participants with a known history of DM. Nonetheless, a history of DM was shown to confer an additional risk of PN in HIV in other reports, including Evans et al., who demonstrated an OR of 1.57 (95\% CI 0.96-2.59, $p=0.080)$ with history of DM in asymptomatic $\mathrm{PN}$ and a significant association of OR 3.15 (95\% CI $1.74-5.70, p=0.001)$ in symptomatic PN amongst patients with HIV [19]. A different report by Anziska and colleagues reported a history of $\mathrm{DM}$ in $19.2 \%$ of the participants 
Table 3 Neuropathy Symptom Score results

\begin{tabular}{|c|c|c|c|c|}
\hline \multirow[t]{2}{*}{ Variables } & Total & HIV only & $\mathrm{HIV}+$ diabetes & $P$ value \\
\hline & $N=136$ & $N=68$ & $N=68$ & \\
\hline
\end{tabular}

Neuropathy symptoms

Symptoms of unsteadiness when walking

$\begin{array}{llllllll}\text { Yes } & 6 & 4.4 \% & 1 & 1.5 \% & 5 & 7.4 \% & 0.208 \\ \text { No } & 130 & 95.6 \% & 67 & 98.5 \% & 63 & 92.6 \%\end{array}$

Burning, aching pain, or tenderness in legs or feet

$\begin{array}{llllllll}\text { Yes } & 23 & 16.9 \% & 16 & 23.5 \% & 7 & 10.3 \% & 0.066 \\ \text { No } & 113 & 83.1 \% & 52 & 76.5 \% & 61 & 89.7 \%\end{array}$

Pricking sensations on legs and feet

$\begin{array}{llllllll}\text { Yes } & 20 & 14.7 \% & 7 & 10.3 \% & 13 & 19.1 \% & 0.226 \\ \text { No } & 116 & 85.3 \% & 61 & 89.7 \% & 55 & 80.9 \%\end{array}$

Regions of numbness on legs and feet

$\begin{array}{llllllll}\text { Yes } & 22 & 16.2 \% & 9 & 13.2 \% & 13 & 19.1 \% & 0.486 \\ \text { No } & 114 & 83.8 \% & 59 & 86.8 \% & 55 & 80.9 \% & \end{array}$

Polyneuropathy ( $\geq 1$ symptom)

\begin{tabular}{llllllll} 
Absent & 92 & $67.6 \%$ & 45 & $66.2 \%$ & 47 & $69.1 \%$ & 0.855 \\
Present & 44 & $32.4 \%$ & 23 & $33.8 \%$ & 21 & $30.9 \%$ & \\
\hline
\end{tabular}

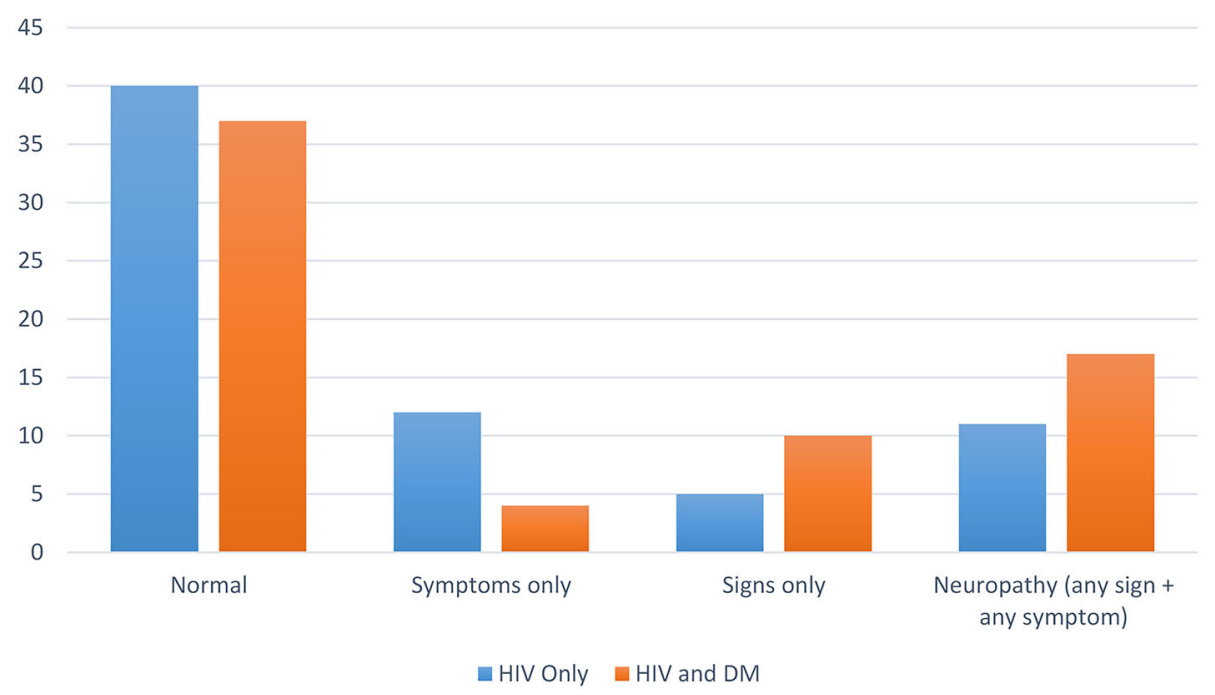

Fig. 2 Prevalence of peripheral neuropathy (percentage) 
Table 4 Factors associated with neuropathy

\begin{tabular}{|c|c|c|c|c|c|c|c|c|c|}
\hline & \multicolumn{3}{|c|}{ Overall $(N=136)$} & \multicolumn{3}{|c|}{ HIV only $(N=68)$} & \multicolumn{3}{|c|}{ HIV + diabetes $(N=68)$} \\
\hline & $\overline{\mathrm{OR}}$ & 95\% CI OR & $P$ value & $\overline{\text { OR }}$ & 95\% CI OR & $P$ value & $\overline{\mathrm{OR}}$ & 95\% CI OR & $P$ value \\
\hline Age & 1.07 & {$[1.02,1.113]$} & 0.004 & 1.04 & {$[0.979,1.102]$} & 0.211 & 1.09 & {$[1.019,1.175]$} & 0.014 \\
\hline Gender (female) & 0.62 & {$[0.263,1.468]$} & 0.278 & 0.55 & {$[0.145,2.094]$} & 0.382 & 0.72 & {$[0.23,2.245]$} & 0.57 \\
\hline BMI (continuous) & 0.98 & {$[0.911,1.053]$} & 0.577 & 0.99 & {$[0.945,1.044]$} & 0.776 & 0.93 & {$[0.817,1.051]$} & 0.238 \\
\hline BMI (underweight) & 3.89 & {$[0.221,68.381]$} & 0.353 & - & - & - & 2.40 & {$[0.124,46.391]$} & 0.562 \\
\hline BMI (overweight) & 1.21 & {$[0.469,3.118]$} & 0.693 & 1.25 & {$[0.297,5.256]$} & 0.761 & 0.98 & {$[0.268,3.602]$} & 0.978 \\
\hline BMI (obese) & 0.58 & {$[0.16,2.073]$} & 0.399 & 1.05 & {$[0.166,6.604]$} & 0.962 & 0.30 & {$[0.049,1.82]$} & 0.19 \\
\hline Duration of HIV & 1.07 & {$[0.996,1.151]$} & 0.063 & 1.08 & {$[0.96,1.219]$} & 0.198 & 1.06 & {$[0.962,1.156]$} & 0.258 \\
\hline CD4 count diagnosis & 1.00 & {$[0.999,1.002]$} & 0.699 & 1.00 & {$[0.998,1.003]$} & 0.744 & 1.00 & {$[0.998,1.002]$} & 0.962 \\
\hline CD4 count last & 1.00 & {$[0.999,1.002]$} & 0.394 & 1.00 & {$[0.999,1.004]$} & 0.287 & 1.00 & {$[0.999,1.001]$} & 0.931 \\
\hline RNA (undetected) & 1.15 & {$[0.46,2.868]$} & 0.767 & 0.43 & {$[0.114,1.613]$} & 0.21 & 2.77 & {$[0.704,10.905]$} & 0.145 \\
\hline
\end{tabular}

$B M I$ body mass index, $R N A$ ribonucleic acid

amongst women in the USA living with HIV in 2009. After multivariate analysis, DM was associated with an OR of 1.45 (95\% CI 1.02-2.08, $p=0.04)$ in HIV DSP [27]. Similar findings were reported earlier in 2005 in a large cohort of 2515 patients in the same country with a reported OR of 1.79 (95\% CI 1.12-2.84, $p=0.014$ [28]. Although our study supports the notion that DM increases the risk of PN in HIV, the sampling technique does not enable analysis of the degree of risk conferred. Most of the patients with DM were diagnosed because of routine random blood sugar checks or HbA1c while undergoing follow-up for HIV infection. The relatively short duration of DM follow-up and well-controlled diabetes is a consequence of screening.

The median age was higher in the HIV and DM group compared to the HIV-only group. Older age was associated with PN with an OR of 1.04 and 1.09 in the two respective groups. This association has been clearly demonstrated in previous studies $[15,19,23,25,26,28,29]$. These results illustrate the contribution of agerelated degeneration of the nerves to the insults by HIV, drugs, and other comorbid conditions like DM (duration) in the occurrence of PN. In our study, female gender was not associated with PN in HIV. This was in contrast to a study done in Kenya that showed an almost tenfold risk in female individuals [15]. The risk of PN was noted to be higher in women who were anemic, proving a possible confounder in the high risk amongst the female patients in the study. Other studies in the same region of subSaharan Africa in Rwanda [25] and Zimbabwe [29] showed no association between female gender and $\mathrm{PN}$.

The association between the level of HIV suppression and $\mathrm{PN}$ has been controversial in previous studies. Advanced disease was noted to be associated with PN in studies done in the USA with CD4 counts lower than 200 conferring odds of 1.39 and 1.64 , respectively $[19,28]$. In contrast, no association was demonstrated between CD4 counts and PN in Kenya [15], Uganda [26], Rwanda [25], and Zimbabwe [29]. These are generally comparable to the findings of this study and supportive of the notion that other factors including nutrition may be contributory to $\mathrm{PN}$ in the African population. Intriguingly, in this study, a suppressed viral load has a positive impact on PN in the HIV and DM group with an OR of 2.77. This was not supportive of the postulated pathogenesis of HIV DSP as viral invasion and replication in the 
peripheral nerves. The potential contribution of $\mathrm{DM}$ as a factor in PN in this subset of patients is unclear. A longer duration of follow-up had a slight positive association with the occurrence of PN in both groups. Significant positive association between the duration of clinical follow up and PN was demonstrated in a study done in North America in 2006 [30]. More recent studies in Rwanda [25] and Nigeria [31] also show the same association.

The strengths of the study lie in the inclusion of two comparative groups in the evaluation of the burden of PN in patients with HIV. Previous reports have excluded patients with diabetes because of the confounding effect on $\mathrm{PN}$. The concurrent HIV and DM group reflects the current and future challenges of comorbidities in the HIV population. Furthermore, the evaluation in relation to age, BMI, and level of disease control of both HIV and DM allowed the assessment of risk factors of PN in the participants. Most of the patients studied were attending regular follow-up clinics and therefore represent a real-world cohort of patients. The findings are therefore generalizable to many settings in Kenya and sub-Saharan Africa. The definition of PN in our study was the presence of both a symptom and a sign using validated and widely utilized criteria.

A limitation of the study was the lack of electrophysiological tests for nerve function studies and reliance on clinical evaluation for the diagnosis of PN. Nerve function tests were not administered because of financial constraints. Although we documented the prevalence of neuropathic symptoms, the burden of the disease and the impact on quality of life were not assessed. Future studies should assess how neuropathy impacts the patients.

\section{CONCLUSION}

Our study demonstrates a higher prevalence of PN in patients with both HIV and DM when compared to HIV alone. Physicians should consider routinely screening patients for PN in HIV-positive patients with DM.

\section{ACKNOWLEDGEMENTS}

We thank the staff and participants at the infectious disease clinic of the Aga Khan University Hospital in Nairobi, Kenya for their cooperation during the conduct of the project. We also acknowledge the input of Aditi Vakil during data collection.

Funding. No funding or sponsorship was received for this study or publication of this article.

Authorship. All named authors meet the International Committee of Medical Journal Editors (ICMJE) criteria for authorship for this article, take responsibility for the integrity of the work as a whole, and have given their approval for this version to be published.

Author Contributions. Uazman Alam contributed to conception and design of the study. Jasmit Shah performed statistical analysis. Werimo Pascal Kuka, Dilraj Singh Sokhi and Reena Shah participated in data collection. All authors participated in the interpretation of the data, the writing, reviewing and editing of the manuscript, and had final responsibility for approving the published version.

Prior Presentation. This study has been earlier presented at the 25th World Neurology Congress, 3-7 October 2021 (virtual).

Disclosures. Werimo Pascal Kuka, Jasmit Shah, Uazman Alam, Dilraj Singh Sokhi and Reena Shah have nothing to disclose.

Compliance with Ethics Guidelines. All phases of this study received approval from the Institutional Ethics Review Committee of the Aga Khan University (Ref. No. 2018/REC-121). The study was conducted in accordance with the Declaration of Helsinki 1964 and its later amendments. Informed consent was obtained from all participants of this study.

Data Availability. The datasets generated during and /or analyzed during this study are 
available from the corresponding author on reasonable request.

Open Access. This article is licensed under a Creative Commons Attribution-NonCommercial 4.0 International License, which permits any non-commercial use, sharing, adaptation, distribution and reproduction in any medium or format, as long as you give appropriate credit to the original author(s) and the source, provide a link to the Creative Commons licence, and indicate if changes were made. The images or other third party material in this article are included in the article's Creative Commons licence, unless indicated otherwise in a credit line to the material. If material is not included in the article's Creative Commons licence and your intended use is not permitted by statutory regulation or exceeds the permitted use, you will need to obtain permission directly from the copyright holder. To view a copy of this licence, visit http://creativecommons.org/licenses/by$\mathrm{nc} / 4.0 /$.

\section{REFERENCES}

1. Deeks SG, Phillips AN. HIV infection, antiretroviral treatment, ageing, and non-AIDS related morbidity. BMJ. 2009;338:a3172.

2. Collaboration of Observational HIVEREiE, Lewden $\mathrm{C}$, Bouteloup $\mathrm{V}$, et al. All-cause mortality in treated HIV-infected adults with CD $4>/=500 / \mathrm{mm}^{3}$ compared with the general population: evidence from a large European observational cohort collaboration. Int J Epidemiol. 2012;41(2):433-45.

3. Smit M, Brinkman K, Geerlings S, et al. Future challenges for clinical care of an ageing population infected with HIV: a modelling study. Lancet Infect Dis. 2015;15(7):810-8.

4. Walensky RP, Paltiel AD, Losina E, et al. The survival benefits of AIDS treatment in the United States. J Infect Dis. 2006;194(1):11-9.

5. Ministry of Health. National AIDS Control Council. Kenya AIDS Response Progress Report. 2018. https://nacc.or.ke/wp-content/uploads/2018/11/ KARPR-Report_2018.pdf. Accessed July 2020.

6. Guaraldi G, Orlando G, Zona S, et al. Premature agerelated comorbidities among HIV-infected persons compared with the general population. Clin Infect Dis. 2011;53(11):1120-6.

7. Shankalala P, Jacobs C, Bosomprah S, Vinikoor M, Katayamoyo P, Michelo C. Risk factors for impaired fasting glucose or diabetes among HIV infected patients on ART in the Copperbelt Province of Zambia. J Diabetes Metab Disord. 2017;16:29.

8. Cho NH, Shaw JE, Karuranga S, et al. IDF Diabetes Atlas: Global estimates of diabetes prevalence for 2017 and projections for 2045. Diabetes Res Clin Pract. 2018;138:271-81.

9. Khoza SP, Crowther NJ, Bhana S. The effect of HIV infection on glycaemia and renal function in type 2 diabetic patients. PLoS ONE. 2018;13(6):e0199946.

10. De Wit S, Sabin CA, Weber R, Worm SW, Reiss P, Cazanave C, El-Sadr W, Monforte AD, Fontas E, Law MG, Friis-Møller N. Incidence and risk factors for new-onset diabetes in HIV-infected patients: the Data Collection on Adverse Events of Anti-HIV Drugs (D: A: D) study. Diabetes Care. 2008;31(6): 1224-9.

11. Kokotis P, Schmelz M, Papadimas GK, et al. Polyneuropathy induced by HIV disease and antiretroviral therapy. Clin Neurophysiol. 2013;124(1):176-82.

12. Ghosh S, Chandran A, Jansen JP. Epidemiology of HIV-related neuropathy: a systematic literature review. AIDS Res Hum Retrovirus. 2012;28(1): $36-48$.

13. Kolson D. Neurologic complications in persons with HIV infection in the era of antiretroviral therapy. Top Antivir Med. 2017;25(3):97-101.

14. Oshinaike $\mathrm{O}$, Akinbami $\mathrm{A}$, Ojo $\mathrm{O}$, et al. Influence of age and neurotoxic HAART use on frequency of HIV sensory neuropathy. AIDS Res Treat. 2012;2012: 961510.

15. Mehta SA, Ahmed A, Laverty M, Holzman RS, Valentine F, Sivapalasingam S. Sex differences in the incidence of peripheral neuropathy among Kenyans initiating antiretroviral therapy. Clin Infect Dis. 2011;53(5):490-6.

16. Albers JW, Pop-Busui R. Diabetic neuropathy: mechanisms, emerging treatments, and subtypes. Curr Neurol Neurosci Rep. 2014;14(8):473.

17. American Diabetes Association. 10. Microvascular complications and foot care: standards of medical care in diabetes-2018. Diabetes Care. 2018;41(Supplement_1):S105-18.

18. Yang Z, Chen R, Zhang Y, et al. Scoring systems to screen for diabetic peripheral neuropathy. 
Cochrane Database Syst Rev. 2018;2018(7): CD010974.

19. Evans SR, Ellis RJ, Chen $H$, et al. Peripheral neuropathy in HIV: prevalence and risk factors. AIDS. 2011;25(7):919-28.

20. Cherry CL, Skolasky RL, Lal L, et al. Antiretroviral use and other risks for HIV-associated neuropathies in an international cohort. Neurology. 2006;66(6): 867-73.

21. Cettomai D, Kwasa JK, Birbeck GL, et al. Screening for HIV-associated peripheral neuropathy in resource-limited settings. Muscle Nerve. 2013;48(4): $516-24$.

22. Mullin S, Temu A, Kalluvya S, Grant A, Manji H. High prevalence of distal sensory polyneuropathy in antiretroviral-treated and untreated people with HIV in Tanzania. Trop Med Int Health. 2011;16(10): 1291-6.

23. Arenas-Pinto A, Thompson J, Musoro G, et al. Peripheral neuropathy in HIV patients in subSaharan Africa failing first-line therapy and the response to second-line ART in the EARNEST trial. J Neurovirol. 2016;22(1):104-13.

24. Maritz J, Benatar M, Dave JA, et al. HIV neuropathy in South Africans: frequency, characteristics, and risk factors. Muscle Nerve. 2010;41(5):599-606.

25. Tumusiime DK, Venter F, Musenge E, Stewart A. Prevalence of peripheral neuropathy and its associated demographic and health status characteristics, among people on antiretroviral therapy in Rwanda. BMC Public Health. 2014;14:1306.

26. Saylor D, Nakigozi G, Nakasujja N, et al. Peripheral neuropathy in HIV-infected and uninfected patients in Rakai, Uganda. Neurology. 2017;89(5): 485-91.

27. Anziska $\mathrm{Y}$, Helzner EP, Crystal $\mathrm{H}$, et al. The relationship between race and HIV-distal sensory polyneuropathy in a large cohort of US women. J Neurol Sci. 2012;315(1-2):129-32.

28. Lichtenstein KA, Armon C, Baron A, et al. Modification of the incidence of drug-associated symmetrical peripheral neuropathy by host and disease factors in the HIV outpatient study cohort. Clin Infect Dis. 2005;40(1):148-57.

29. Kiwuwa-Muyingo S, Kikaire B, Mambule I, et al. Prevalence, incidence and predictors of peripheral neuropathy in African adults with HIV infection within the DART trial. AIDS. 2014;28(17):2579-88.

30. Ances BM, Vaida F, Rosario D, et al. Role of metabolic syndrome components in HIV-associated sensory neuropathy. AIDS. 2009;23(17):2317-22.

31. Ekenze OS, Nwosu CM, Ogunniyi A. Frequency and risk factors for distal sensory polyneuropathy in HIV infection in a developing country. Int J STD AIDS. 2014;25(3):178-83. 